\title{
An Ecological Discourse Analysis of English Textbook "Oxford English" from the Perspective of Transitivity and Ergativity
}

\author{
Hui Li \\ School of Foreign Languages and Cultures, Nanjing Normal University, Nanjing 210000, Jiangsu, China
}

\begin{abstract}
Ecological discourse analysis reflects how our ways of meaning shape our responses to the environment. In recent years, ecological discourse analysis guided by systemic-functional linguistics mostly based on transitivity system, while the classification of clauses' ecological semantic orientation needs to be refined. The existing ecological discourse analysis is less focused on educational discourse. Therefore, under the comprehensive model of transitivity and ergativity, this research refines the process types and participant roles, and explores the semantic ecological orientation of different processes under the guidance of ecological philosophy. By combining qualitative and quantitative analysis, the Oxford English textbook is taken as an example to reveal the ecological perspective embedded in the educational discourse and to inform the ecological education in teaching practice. Educational discourse should increase the proportion of beneficial discourse in the text to enhance students' sense of ecological responsibility.
\end{abstract}

Keywords: Ecological discourse analysis, Transitivity, Ergativity, Ecological ideology.

\section{Introduction}

\subsection{Research Background}

Ecolinguistics is an emerging branch of linguistics formed by the combination of ecology and linguistics (Fan Junjun, 2005; Han Jun, 2013; Huang Guowen, 2016). It is the general term for all studies involving the relationship between language and ecology (Fill \& Mühlhusler, 2001; Fill \& Penz, 2018). At present, there are two paradigms that are widely spread in the academic community: Haugen's model and Halliday's model. The Haugen model, also known as the ecology of language, focuses on language diversity, language contact, and endangered languages. It believes that linguistic ecology should study "the interactions between any particular language and its environment" (Haugen, 1972: 57), and compares this relationship with the ecological relationship between specific animal or plant species and their living environment, hence it is called the metaphorical model. While Halliday's model focuses on the ecological impact of language, i.e., "how our ways of meaning shape our impact on the environment" (Halliday, 2007: 14), emphasizes the role of language plays in environmental issues, and highlights the social responsibility of linguists (Huang Guowen, 2016; He Wei and Wei Rong, 2018).

With the increase of ecological problems, ecological protection has become one of the focuses of the whole world. Continuous efforts are being made for ecological improvement in variuos fields. Ecological discourse analysis has become one of the main research paths in ecological linguistics (Alexander \& Stibbe, 2014). Ecological discourse analysis extends the scope of discourse research to other species in the ecosystem except for human beings. The research topics include environmental advertise, environmental journalism, as well as natural poetry in literary works. Stibbe promotes the analysis of different types of discourse from an ecological perspective. How educational discourse constructs the relationship between mankind and nature plays an important role in shaping people's ecological outlook. However, there is a lack of research on educational discourse from the perspective of ecological linguistics. Systemic functional linguistics is a "problem-oriented" as well as "applied linguistics", which provides a relatively complete theoretical support for ecological discourse analysis. However, ecological discourse analysis tends to be conducted from the perspective of transitivity, and rarely adopts the pattern of ergativity.

\subsection{Purpose and Significance}

In accordance with the requirements of English teaching, this research attempts to make a deep ecological discourse analysis of Oxford English textbooks published by Shanghai Education Publishing House. It focuses on two research questions: (1) Do the textbooks contain the three types of ecological discourse (beneficial, ambivalent and destructive ecological discourse)? If yes, how are the three types of discourse distributed in the textbooks? (2) How do high school students understand ecological discourse in the textbooks?

\section{Literature Review}

SFL is a famous language theory that many linguists devoted themselves to, such as Halliday (2014). Halliday (2014) states that SFL can be seen as a functional-semantic approach to examine how people use language in different contexts and how language is organized as a semiotic system. According to Martin (2002), SFL pays longstanding attention to the discourse analysis, and Halliday (2014) uses three meta-functions to explore how language is used. The present study will not have further discussions of all the three meta-functions and will focus mainly on the experimental function which is realized by the transitivity system to reveal how the language express experiences, related participants as well as circumstances (Halliday, 2014).

The analysis of ecological discourse guided by systemic-functional grammar mostly focuses on the analysis 
of materiality, analyzing the construction of the text's image of nature by exploring the participant roles assumed by natural participants (Huang, Guowen Chen, Yang, 2017; Goatly, 2002). However, the existing studies have relatively simplified the analysis of the and-objectivity of the clause, taking the material process as an example, the studies only distinguish the actor and the target, ignoring the complexity of the semantic representation of the clause of the material process. First, the role assignment of actor and target characterizes the material process as an actor-actee dichotomy, which cannot reasonably explain the absence of an action object in the clause for intransitive verbs. Second, this interpretation does not reflect the language user's use of linguistic strategies to hide the actor.

\subsection{Transitivity System}

Transitivity system is a semantic system in the ideational meta-function. It divides all the human experiences in real life into several processes and characterizes people's experience activities through three components of the clauses' process types, participants and circumstance respectively. Early researchers choose to use critical discourse analysis to explore hidden ecological ideologies in the transitivity system. However, few studies use ecological discourse analysis and focus on the transitivity system in other genres of discourses except news from the perspective of eco-linguistics to unveil its hidden ecological minds.

In the transitivity system, there are six main processes which can organize human experiences. Each process type has a unique schema to construe a special experience (Halliday, 2014). The material process centers on the outside world and outer experience, so that it emphasizes "doing", expressing that some entities do somethings, or their actions have an impact on others. The mental process focuses on the inner experiences or the world of people's consciousness. It consists of the obligatory Senser, the Process and a Phenomenon. Relational process reflects the process of being with two modes: attributive and identifying processes with participants of Carrier-Attribute and Identifier-Identified respectively. Behavioral process refers to the physiological and psychological activities, locating on the boundary of the mental and material process with the participant of Behaver as a conscious being all the time. Moreover, the verbal process, is located on the boundary of the mental and relational processes with three main participants: Sayer, Receiver and Verbiage. Last but not least, there is an existential process which usually applies the subject "there" which has no representational function at the beginning of the sentence and also includes an object or event that is labeled as Existent.

\subsection{Ergativity System}

Halliday called the key participants in the process clause "intermediary", which is the basis for the existence of the clause process. "It is through intermediary that the process can be realized". Mediation and process constitute the core of clause experiential structure. If the process of the clause is "intermediate", it belongs to the middle sentence. A clause is an ergative sentence if the process is caused by another participant other than an intermediary. "The focus of case analysis is whether the action process is spontaneous or caused by another entity", which reveals the construction of causality in the text. It can be seen that the advantage of case analysis lies in its ability to reflect the external causes of action and reveal the construction of causality in the text.

The different perspectives of the ergistic model make it complement the deficiency of the transitive model. There is only one participant in the intransitive verb clause, which cannot be reasonably explained from the perspective of the initiation, reception and energy level of the action. However, the middle verb process can be interpreted as a spontaneous activity without human intervention by using the middle verb in the case pattern. In addition, the distinction between the active voice and the passive voice in the ergative mode also helps to highlight the intention of the target text to conceal the agency, thus revealing the ideological meaning and position of the language strategy. Transitivity model analysis and case model analysis focus on different emphases, the combination of the two can further explore the ecological significance of discourse.

\subsection{Ecosophy}

Participant roles and processes together constitute the core of the experiential structure of the clause. Although the transitive-ergative model can refine the participant roles, the semantics of process verbs need to be considered to determine the ecological orientation of the clause. Whereas the same participant roles with different semantic process verbs may convey different ecological orientations. Therefore, in order to judge the ecological orientation of the clause as a whole, it is necessary to classify the clause processes and analyze whether their ecological orientation is ecologically beneficial or destructive. The judgment criterion is based on the ecological ethical and moral concepts held by the discourse analyst, i.e., the ecosophy.

The guideline of EDA of this thesis: "Diversity and Harmony, Interaction and co-existence". Ecosophy is first proposed by Naess (1973), short for ecological philosophy. Ecosophy has its essebtial value for ecolinguistics and is the criterion for the judgement of ecological orientation of world language system and discourse (He 2018). Stibbe (2015:11) suggests that each ecolinguist will have their own set of philosophical principles to judge stories against, reflecting their own values and priorities, but all will have in common a consideration of the interrelationships of humans with other organisms and the physical environment. In China, Huang (2017), a director of the study on ecolinguistics in China and the Chinese Regional Representative of the International Ecolinguistics Association, argues we need to carry out EDA draw on Eastern ecosophy, especially those from Chinese classical philosophies, such as Lao-tzu, Confucius and Chuang-tzu, etc. Under the theory that "man is an integral part of nature", Huang introduces the ecosophy of "unity of opposites, balance and harmony."

\section{Ecological Discourse Analysis of Educational Discourse Based on Transitivity and Ergativity}

This section attempts to combine transitive and ergative modes, and classify process semantics. Taking educational discourse as an example to explore the transitivity analysis 
model of ecological discourse, so as to reveal the values contained in the text. Examples are selected from the fifth module of "Oxford English" published by Shanghai Education Publishing House. Based on the framework of transitivity analysis, this study analyzes clauses involving natural participants in textbooks, and classifies the ecological orientation of clauses by examining the roles of participants and process semantics selected through transitive-ergative integrated system.

\subsection{Ecological Discourse Analysis based on Transitivity and Ergativity}

Firstly, this study annotates and codes sentences involving natural participants in the textbook, and then discusses the semantic characteristics of process clauses by combining transitive analysis and ergative analysis. Based on this model, the ecological orientation of the sentences is determined and the ecological attributes of clauses are annotated according to the ecological philosophy of "respect for life", "equality of all things" and "harmonious coexistence".

\subsubsection{Eco-beneficial clauses}

The analysis found that the ecologically beneficial discourse in textbooks is mainly represented by the following linguistic structures.

(1) They are part of the food chain-insects and other animals eat them or use their products, and these insects and animals will be eaten by yet other animals.

Natural participants act as actors/acting agents, with process semantics representing life activities, showing that natural participants (mostly animals) engage in foraging, entertainment, courtship, reproduction and other activities. Nature is represented as an active initiator of actions, endowed with more power, which highlights the subjective initiative of natural participants.

(2) It will be good to increase the amount of things we recycle, and teach people ways of living that do not harm the environment.

(3) There are many factories and industries which control the amount of pollution they produce, and are very careful to spend money repairing any damage they cause.

The natural participant acts as a target. Although the power level of its role is low, the semantics associated with it expresses the cherishment of nature, which reflects that human beings actively intervene in nature and exert positive power.

(4) Last but not least, you can plant a tree, because trees absorb the carbon dioxide in the air to produce oxygen.

(5) ...a wide range of fish and wildlife that live freely in or along the river.

Natural participants act as actors/intermediaries, describing the spontaneous and autonomous activities. Moreover, process verbs mostly express playfulness, which belongs to natural life activities and reflects their lives without human intervention.

(6) They are part of the food chain-insects and other animals eat them or use their products.

Natural participants act as perceivers in the psychological process. It is endowed with "unique" attributes of human beings, such as natural feeling and cognition, which helps to build a harmonious ecological view of equality between human and nature.

By endowing nature with power, self-determination, consciousness and perception, the above-mentioned language recognizes the inherent value of nature and its equal status with human beings. Additionally, in view of the fragile ecology, shaping nature as a vulnerable image will help awaken readers' awareness of ecological responsibility.

\subsubsection{Eco-destructive clauses}

However, when the roles mentioned above are matched with different meanings, they may convey completely different ecological orientations and construct nature images that are not conducive to ecological harmony.

(7) There will be a small number of fish left in the future.

The role of dynamic author/intermediary is spontaneous and independent. If it is associated with the semantic meaning of ecological degradation, it is not conducive to revealing the root cause of ecological problems or stimulating human protection consciousness and behavior to create an image of ecological degradation occurring spontaneously and unrelated to human activities.

(8) Much sea life is being destroyed by fishing boats as well. These boats catch large number of fish without giving them time to lay eggs.

(9) Rapid development and increase in population have meant that the amount of water taken from the river is rising, and the waste being put back into the river has been increasing.

When the natural actor acts as the target/intermediary (agent), it indicates that the agent still exerts influence on nature, and nature is at the lower end of the hierarchy of power and power. If the semantic collocation with the image of natural weakness is use and destruction, nature is represented as a tool and victim to realize human interests.

(10) Many places have been destroyed and many plants and animals have died.

(11) The white flag dolphin was last seen several years ago, though scientists are still hopeful that the animal has survived.

In the passive clause, the natural participant acts as the target/intermediary (no agent), and the agent that was originally the subject is downgraded to adverbial or even omitted, which conceals the external cause of the natural destruction event and hides the subject of responsibility, which is not conducive to improving the ecological 
consciousness of readers and tends to be ecological destruction type in terms of ecological orientation.

\subsubsection{Eco-ambivalent clauses}

Relationship process and existence process semantically represent relationship or existence, which do not involve specific actions and behaviors. The ecological information contained is more complicated which can only be determined based on specific semantic information. If a certain discourse is between beneficial and destructive, on the one hand, the world outlook and ideology conveyed are consistent with the ecological philosophy of the analyst, on the other hand, there are inconsistent or conflicting aspects. This kind of discourse belongs to eco-ambivalent discourse.

(12) The amount of rubbish we produce is turning into a big problem; we need to think more about recycling our waste.

It is recognized that "human beings should recycle wastes", which is consistent with the ecological concept of "harmonious coexistence", belongs to the beneficial element of the clause. Whereas "The amount ... problem" belongs to the destructive element of this sentence, so this sentence is an eco-ambivalent clause.

(13) After decades of destroying nature and using up natural resources, many developed nations are now concerned about saving nature rather than developing or destroying it.

It is recognized that "human beings should save nature", which is consistent with the ecological concept of "harmonious coexistence", belongs to the beneficial element of the clause. Whereas "using up natural resources" belongs to the destructive element of this sentence, so this sentence is an eco-ambivalent clause.

(14) Not everything that is best for nature is good for people.

It expresses "anthropocentrism", which ignores the survival and well-being of other ecological factors in the ecosystem except for human beings. The meaning expressed in example (14) is contrary to the ecological concept of "respect for life" and belongs to eco-ambivalent clause.

\subsection{Quantitative Data of Ecological Attributes of Process Clauses}

It should be noted that the events characterized by individual sentences, whether humans use natural resources or humans protect nature, are ways of energy interaction among members within the ecosystem, and individual clauses cannot be used as a basis for judging the ecological meaning of the discourse as a whole. However, the collection of small sentences in a discourse will foreground a specific image of nature, and the human perception toward nature is implied behind this selective presentation of the image of nature. Therefore, the qualitative analysis of clauses needs to be combined with quantitative statistics in order to distinguish the ecological view of the discourse.

\begin{tabular}{|c|c|c|c|c|}
\hline & Text & Eco-beneficial & Eco-destructive & Eco-ambivalent \\
\hline \multirow{3}{*}{ M5U2 } & Text 1 & 10 & 4 & 3 \\
\cline { 2 - 5 } & Text 2 & 7 & 4 & 2 \\
\cline { 2 - 5 } & Text 3 & 7 & 2 & 3 \\
\hline
\end{tabular}

M5U3

\begin{tabular}{|l|l|l|l|}
\hline Text 1 & 3 & 7 & 2 \\
\hline Text 2 & 4 & 7 & 1 \\
\hline Text 3 & 4 & 8 & 6 \\
\hline
\end{tabular}

Through the quantitative and qualitative analysis of ecological discourse, it can be seen that the text of Unit 2 is relatively positive in terms of ecological orientation. Grammatically, although nature is in a weak position (as a target/ intermediary), the semantic collocation of protection indicates that human beings cherish nature and highlight the positive role of human beings in natural ecology, which is mostly ecologically beneficial discourse. From the point of view of content, the text of unit 2 discusses the choice between environment and economy, emphasizing that we should protect the environment while pursuing benefits. Text 2 introduces two special projects proposed by the Government in response to the pollution problems of the Yangtze River, which also take into account the protection of animals and plants. Text 3 advocates a low-carbon life. The three texts all convey the ecological philosophy view of respecting the intrinsic value of nature and have positive ecological education significance. The three essays in unit 3 make extensive use of ergative sentences, use the natural subject as the role of the actor, shaping them into the objects of human activities. By using passive mood to hide the subject of responsibility, it weakens the natural power and evades the responsibility of human beings in the process of natural degradation. It hardly plays an ecological education significance. From the perspective of content, the themes of unit 3 are cloning technology and genetically modified food. These texts put nature under human needs as tools and resources, and their own value of existence is weakened. Contrary to the ecological philosophy view of respecting the intrinsic value of nature, most of them belong to the semantic representation of ecological destruction.

Therefore, no matter from the comparison of language structure, content or quantitative data, it is confirmed that the text ecology of Unit 2 is stronger than that of Unit 3. Therefore. It also shows that the analytical framework and research path of this study have certain reference value for revealing the ecological significance of discourse.

\section{Discussion and Conclusion}

How the educational discourse represents the relationship between human beings and nature is essential for developing a positive ecological awareness. Identifying the harmonious relationship between man and nature can stimulate the initiative of ecological protection. Moreover, a certain analytical model is crucial to guide ecological education in teaching practice.

Based on the theory of systemic-functional linguistics and transitivity system, this paper synthesizes two experiential representations, transitivity model and ergative model, to refine the role of clause participants and give them different ecological attributes. The empirical study shows that the mutual collaboration in analyzing transitivity and ergativity can better reveal the ecological attributes of process clauses. At the same time, following the ecological philosophy, the semantic classification of clause process is carried out to distinguish ecologically beneficial, ecologically ambiguous and ecologically destructive discourse. Keep preserving and 
developing eco-beneficial clauses and using more "Green language" in daily life so as to cultivate eco-beneficial ideologies to protect the whole environment. Make human beings realize their eco-destructive ideologies in their language and the influence of these languages on nature.

Additionally, linguists should focus on eco-ambivalent clauses in order to make more "Green language" in the world to shape an ecological world. This study provides practical ideas for exploring the ecological view of educational discourse transmission through theoretical demonstration and case study. Therefore, the selection of educational discourse should take "ecological awareness" as an important factor and advocate the adoption of beneficial discourse in order to better serve ecological education.

\section{References}

[1] Alexander, R \& A. Stibbe. From the analysis of ecological discourse to the ecological analysis of discourse [J]. Language Sciences, 2014(41):104 -110.

[2] Dong Dian. Multidimensional Ecological Discourse Analysis of News Discourses in the New Era [J]. Technology Enhanced Foreign Language Education, 2021(1): 92-97.

[3] Fan Junjun. A Review of the Researches on Ecolinguistics $[\mathrm{J}]$. Foreign Language Teaching and Research, 2005(2): 110-115.

[4] Fill, A. \& P. Mühlhusler. The Ecolinguistics Reader: Language, Ecology and Environment [C]. London \& New York: Continuum, 2001.

[5] Fill, A. \& H. Penz. The Routledge Handbook of Ecolinguistics [M]. New York: Routledge, 2018.

[6] Goatly, A. The representation of nature on the BBC World Service [J]. Text, 2002(1): 1- 27.

[7] Halliday, M. A. K. An Introduction to Functional Grammar (3rd edition) [M]. London: Arnold, 2004.

[8] Halliday, M. A. K. Applied linguistics as an evolving theme [A]. In J. Webster. Collected Works of M. A. K. Halliday: Language and Education, Volume 5 [C]. London: Continuum, 2007.

[9] Halliday, M. A. K. \& C. Matthiessen. Halliday's Introduction to Functional Grammer (4th edition). London: Routledge, 2014.

[10] Han Jun. The Review of the Domestic Research on Ecolinguistics [J]. Language Teaching and Linguistic Studies, 2013(4): 107-112.

[11] Haugen, E. The ecology of language [A]. In A. Fill. \& P. Mühlh usler (eds.). (2001). The Ecolinguistics Reader: Language, Ecology and the Environment [C]. London \& New York: Continuum, 1972.

[12] He Wei. A Few Key Issues Concerning Ecolinguistics as a Discipline. [J]. Foreign Languages in China, 2018(4): 1, 11-17.

[13] He Wei, Wei Rong. Development and Disciplinary Attributes of Ecolinguistics [J]. Social Sciences Abroad, 2018(4): 113-123.

[14] Huang Guowen. The Origin and Evolution of Ecolinguistics [J]. Foreign Languages in China, 2016(1): 9-12.

[15] Huang Guowen. From Systemic Functional Linguistics to Ecologuistics $[\mathrm{J}]$. Foreign Language Education, 2017(05): 1-7.
[16] Huang Guowen, Chen Yang. An Ecolinguistic Analysis of Emily Dickinson's “A Bird Came down the Walk" [J]. Foreign Language and Literature, 2017(2): 61-66.

[17] Martin, J. R. Meaning beyond the clause: SFL perspectives [J]. Annual Review of Applied Linguistics, 2002(22): 52-74.

[18] Arne Naess. The Shallow and The Deep, long- Range Ecology Movement. A Summary [J]. Inquiry, 1973(16): 95-100.

[19] Stibbe, A. Animals Erased: Discourse, Ecology, and Reconnection with the Natural World [M] Middle town: Wesleyan University Press, 2012.

[20] Stibbe, A. Ecolinguistics: Language, Ecology and the Stories We Live By [M]. London: Routledge, 2015. 